\title{
Psychotropic medication use among patients with a traumatic brain injury treated in the intensive care unit: a multi-centre observational study
}

\author{
Juho Vehviläinen ${ }^{1}$ (D) Markus B. Skrifvars ${ }^{2} \cdot$ Matti Reinikainen $^{3} \cdot$ Stepani Bendel $^{3} \cdot$ Ivan Marinkovic $^{4}$. \\ Tero Ala-Kokko ${ }^{5}$ Sanna Hoppu ${ }^{6} \cdot$ Ruut Laitio $^{7}$ - Jari Siironen ${ }^{1} \cdot$ Rahul Raj $^{1}$
}

Received: 26 April 2021 / Accepted: 26 July 2021/ Published online: 11 August 2021

(C) The Author(s) 2021, corrected publication 2021

\begin{abstract}
Background Psychiatric sequelae after traumatic brain injury (TBI) are common and may impede recovery. We aimed to assess the occurrence and risk factors of post-injury psychotropic medication use in intensive care unit (ICU)-treated patients with TBI and its association with late mortality.

Methods We conducted a retrospective multi-centre observational study using the Finnish Intensive Care Consortium database. We included adult TBI patients admitted in four university hospital ICUs during 2003-2013 that were alive at 1 year after injury. Patients were followed-up until end of 2016. We obtained data regarding psychotropic medication use through the national drug reimbursement database. We used multivariable logistic regression models to assess the association between TBI severity, treatment-related variables and the odds of psychotropic medication use and its association with late all-cause mortality (more than 1 year after TBI).

Results Of 3061 patients, $2305(75 \%)$ were alive at 1 year. Of these, 400 (17\%) became new psychotropic medication users. The most common medication types were antidepressants (61\%), antipsychotics (35\%) and anxiolytics (26\%). A higher Glasgow Coma Scale (GCS) score was associated with lower odds (OR 0.93, 95\% CI 0.90-0.96) and a diffuse injury with midline shift was associated with higher odds (OR 3.4, 95\% CI 1.3-9.0) of new psychotropic medication use. After adjusting for injury severity, new psychotropic medication use was associated with increased odds of late mortality (OR 1.19, 95\% CI 1.19-2.17, median follow-up time 6.4 years).

Conclusions Psychotropic medication use is common in TBI survivors. Higher TBI severity is associated with increased odds of psychotropic medication use. New use of psychotropic medications after TBI was associated with increased odds of late mortality. Our results highlight the need for early identification of potential psychiatric sequelae and psychiatric evaluation in TBI survivors.
\end{abstract}

Keywords Traumatic brain injury $\cdot$ Psychiatric sequelae $\cdot$ Intensive care $\cdot$ Psychotropic medication

This article is part of the Topical Collection on Brain trauma

Juho Vehviläinen

juho.vehvilainen@helsinki.fi

1 Department of Neurosurgery, Helsinki University Hospital and University of Helsinki, Topeliuksenkatu 5, P.B. 266, 00029 HUS Helsinki, Finland

2 Department of Emergency Care and Services, University of Helsinki and Helsinki University Hospital, Helsinki, Finland

3 Department of Intensive Care, Kuopio University Hospital \& University of Eastern Finland, Kuopio, Finland
4 Department of Neurology, Helsinki University Hospital and University of Helsinki, Helsinki, Finland

5 Department of Intensive Care, Oulu University Hospital \& University of Oulu, Oulu, Finland

6 Department of Intensive Care and Emergency Medicine Services, Tampere University Hospital \& University of Tampere, Tampere, Finland

7 Department of Intensive Care, Turku University Hospital \& University of Turku, Turku, Finland 


\section{Introduction}

Survivors of traumatic brain injury (TBI) and intensive care unit (ICU) treatment suffer from long-term neurological, psychiatric and social burden, in spite of favourable functional recovery [10, 22, 26, 37-39]. Patients with TBI may suffer from various psychiatric problems, such as depression, bipolar affective disorder and anxiety disorders, which are likely to impede recovery [12, 17, 29, 33, 37]. In general, patients suffering from any trauma seem to be susceptible to psychiatric problems following ICU admission [35]. In addition, a significant proportion of patients with TBI have psychiatric comorbidities prior to injury, the three most common being substance use disorder, major depressive disorder and anxiety [39]. Indeed, psychiatric comorbidities are among the strongest predictors of late mortality (death 1 year or later after discharge) among patients with TBI [4].

In recent years, there has been an increase in the use of psychotropic medications among the general population in many high-income countries. In Finland, the prevalence of psychotropic medication use was $18 \%$ in the adult population in 2013 [40]. Of all psychotropic medications, antidepressants is the most common medication used among TBI patients [2]. In Europe between the years 2000 and 2010, the prevalence of antidepressant use increased from 3.7 to $7.2 \%$ [24]. In parallel, the global incidence of TBI is increasing [14]. Thus, given the negative impact of psychiatric sequelae on recovery of patients with TBI, there is a need to understand the complex interplay between preand post-injury psychotropic medication use and TBI care.

Accordingly, we designed the current study to gain data on the prevalence of psychotropic medication use, as a proxy of psychiatric disorders, among patients with TBI treated in the ICU. We set out to study whether certain injury types, or any particular clinical course, would associate with the need for psychotropic medications among TBI survivors. We further studied whether new or previous use of psychotropic medications was associated with in increased risk for late all-cause mortality in 1-year survivors. We hypothesized that (1) the use of psychotropic medications would be common both pre- and post-TBI, (2) that higher TBI severity would increase the use of psychotropic medication in survivors and (3) that TBI survivors using psychotropic medications would have an increased risk for late mortality.

\section{Methods and materials}

The ethics committee of Helsinki University Hospital (194/13/03/14 §97), the Finnish National Institute for Health and Welfare (THL/713/5.05.01/2014 and THL/1298/5.05.00/2019), Statistics Finland (TK53-1047-14), the Social Insurance Institution of Finland (Kela 23/522/2018), the Office of the Data Protection Ombudsman (Dnro 2713/402/2016 28.10.16) and all the participating university hospitals' research committees approved this study. The study adhered to the Strengthening the Reporting of Observational studies in Epidemiology (STROBE) guidelines. We retrieved data on mortality from the Finnish population register on December 31, 2016 (available for all Finnish residents).

\section{Study design and population}

We performed a multi-centre retrospective observational study using data that were prospectively collected to the Finnish Intensive Care Consortium (FICC) database. The FICC database is a nationwide database including all ICUtreated patients from the majority of all Finnish ICUs [34]. In Finland, all specialized tertiary intensive care of patients with TBI is centralized to five university hospital ICUs. Four of these ICUs, covering approximately two-thirds of the population in Finland, participate in the FICC. From these four tertiary ICUs, we included all adult TBI patients (age $\geq 18$ years) admitted between January 1, 2003, and December 31, 2013 (readmissions excluded). TBI patients were identified by Acute Physiology and Chronic Health Evaluation (APACHE) III diagnostic codes and the diagnoses were manually verified by screening health records and reviewing primary head computer tomography (CT) scans [31]. Patients were excluded, if no CT was available, Glasgow Coma Scale (GCS) or pre-admission functional status was missing.

\section{Definition of covariates}

ICU-related variables were retrieved from the FICC database. The GCS score is defined according to the APACHE II definition as the worst measured GCS score during the first ICU day [20]. For intubated and/or sedated patients, the last reliable GCS score preceding sedation is used. The FICC uses a modified version of the World Health Organization/Eastern Cooperative Oncology Group (WHO/ECOG) classification for pre-admission functional status (fit for work or equal, unfit for work but independent in self-care, partially dependent in self-care, totally dependent in selfcare) [27]. We classified all admission CT scans according to the Marshall CT classification [25]. We defined a significant chronic comorbidity according to the APACHE II and Simplified Acute Physiology Score (SAPS) II [20, 23]. We defined Intracranial Pressure (ICP) monitoring through the Therapeutic Intervention Scoring System (TISS) 76 that is routinely collected for the FICC database [19]. We used the NOMESCO Classification of Surgical Procedures Finland 
(NCSP-F) for the definition of external ventricular drain (EVD, NCSP-F code AAF00), craniotomy for hematoma evacuation (NCSP-F code AAD00, AAD05, AAD15) and for decompressive craniectomy (NCSP-F code AAK80).

\section{Psychotropic medication purchases}

In Finland, patients get physician-prescribed medication, including psychiatric medication, reimbursed by the Social Insurance Institution with a maximum out-of-pocket payment of roughly 600 euros per calendar year. After the outof-pocket ceiling is reached, patients pay 2.50 euros per medication and per purchase regardless of the cost.

We obtained data on purchased psychotropic medication from the Social Insurance Institution from January 1, 2003, to December 31, 2013. We defined psychotropic medication as an Anatomical Therapeutic Chemical (ATC) classification system code of N05A-C* (N05A = antipsychotics, $\mathrm{N} 05 \mathrm{~B}=$ anxiolytics, N05C $=$ hypnotics and sedatives) and N06A-C* $($ N06A = antidepressants, N06B = psychostimulants, $\mathrm{N} 06 \mathrm{C}=$ psycholeptics and psychoanaleptics in combination, excluding N06D*, anti-dementia drugs) [40]. We considered psychotropic medication use if the patient purchased the medication at least two times. We defined start of psychotropic medication use at the date of first purchase. We separately classified according to pre-TBI use and postTBI use.

\section{Statistical methods}

We used SPSS Statistics 25.0 for mac OS (IBM Corp, Armonk, NY) and Stata Statistical Software for macOS
(StataCorp LP, College Station, TX) for the statistical analyses.

We compared categorical data between groups using a two-sided $\chi^{2}$ test. We tested continuous data for skewness. We present normally distributed data as means with standard deviations (SD) and non-parametric data as medians with interquartile range (IQR). We compared normally distributed data between groups using a $t$-test and non-parametric data using a Mann-Whitney $U$ test.

We tested the association between risk factors and the odds of use of psychotropic medication using multivariable logistic regression models. In the logistic regression models, we adjusted for age, gender, GCS score, chronic comorbidity, WHO/ECOG classification, Marshall CT classification and a modified SAPS II (excluding age, GCS score and chronic comorbidity) [31].

We tested the association between pre-TBI psychotropic medication use and 1-year mortality and between post-TBI psychotropic medication use and late mortality (in 1-year survivors) using logistic regression analysis, adjusting for the aforementioned factors. We defined late mortality as allcause mortality that happened later than 1 year after TBI, as most of the death attributable to TBI occurs in the first year [1].

\section{Results}

Of 3061 patients, 1195 (39\%) had a history of psychotropic medication use prior to the TBI (Fig. 1). Of the 3061 patients, 2305 (75\%) were alive 1 year after the TBI. Of these, 866 patients $(38 \%)$ had a history of psychotropic medication use prior to TBI, 400 patients (17\% of all survivors)
Fig. 1 Flow chart. Abbreviations: TBI, traumatic brain injury; FICC, Finnish Intensive Care Consortium; CT, computerized tomography; GCS, Glasgow Coma Scale

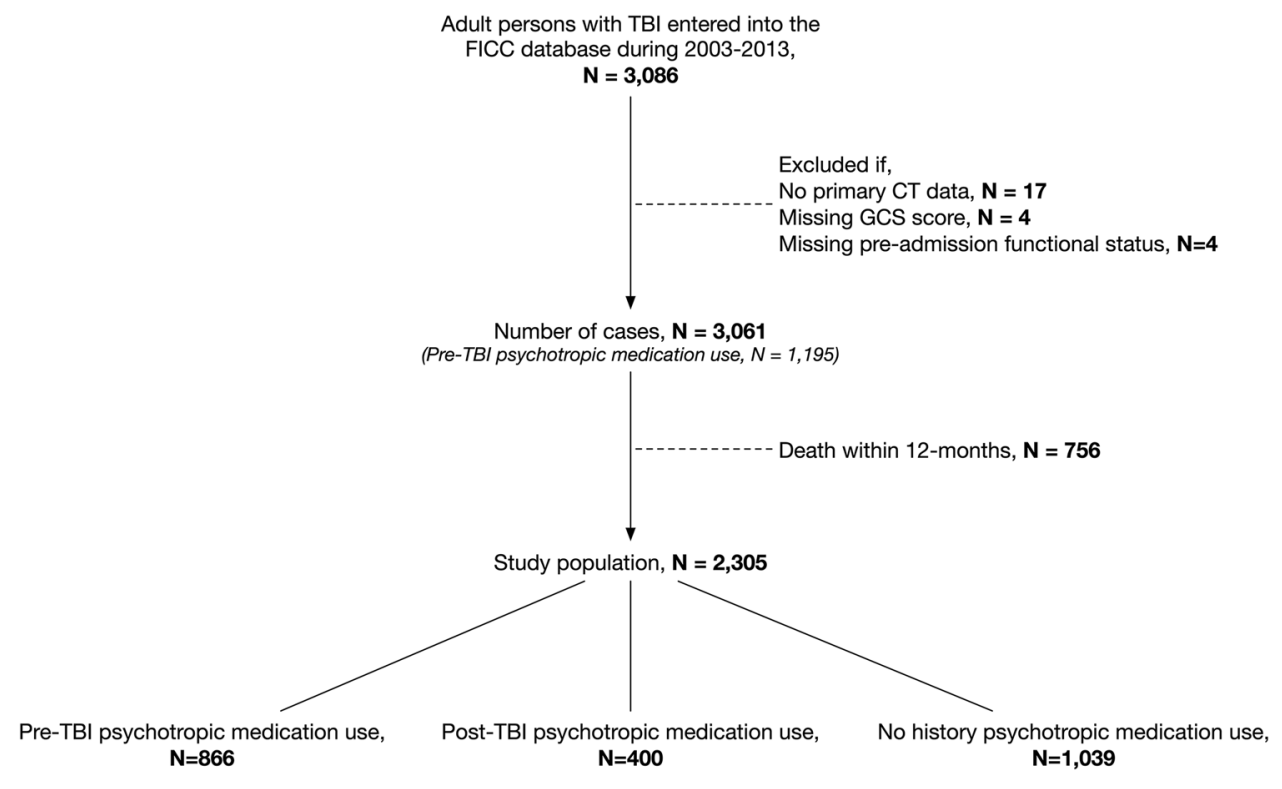


were prescribed a psychotropic medication after TBI and 1039 patients (45\%) had no prior or new history of psychotropic medication use.

Median time from first psychotropic medication purchase to TBI was 4.0 years (IQR 2.0-6.4) for those with a history of psychotropic medication use prior to TBI. Median time from TBI to first psychotropic medication purchase was 0.6 years for those without a history of prior use (IQR $0.2-1.5$ years).

Patients with a history of pre-TBI use of psychotropic medication $(N=1195)$ had been less frequently fit for work $(51 \%$ vs. $68 \%)$, were more often female ( $29 \%$ vs. $19 \%)$ and had more severe chronic comorbidities $(11 \%$ vs. $7 \%)$ than patients without a pre-TBI history of psychotropic medication use (Table 1).

One-year survivors with a new post-TBI psychotropic medication use had lower GCS scores (median 9 vs. 12), had been less frequent fit for work (67\% vs. $76 \%)$, more often underwent craniotomy for mass lesion ( $42 \%$ vs. $31 \%$ ), were more often mechanically ventilated ( $73 \%$ vs. $56 \%)$, had higher SAPS II scores (34 vs. 28 ) and more often a mass lesion on the admission head CT scan ( $41 \%$ vs. $35 \%)$ than 1 -year survivors without a need for psychotropic medication (Table 2).

In patients with pre-TBI psychotropic medication use, the most common psychotropic drugs were

Table 1 Baseline characteristics and treatment of traumatic brain injury patients

\begin{tabular}{|c|c|c|c|c|}
\hline Variables & $\begin{array}{l}\text { All patients } \\
(N=3061)\end{array}$ & $\begin{array}{l}\text { Pre-TBI psychotropic medi- } \\
\text { cation use }(N=1195)\end{array}$ & $\begin{array}{l}\text { No pre-TBI psychotropic } \\
\text { medication use }(N=1866)\end{array}$ & $p$-value \\
\hline Age, median (IQR) & $56(41,67)$ & $57(45,68)$ & $54(38,66)$ & $<0.001$ \\
\hline $18-40$ years & $745(24 \%)$ & $226(19 \%)$ & $519(28 \%)$ & $<0.001$ \\
\hline $41-64$ years & $1434(47 \%)$ & $611(51 \%)$ & $823(44 \%)$ & \\
\hline$\geq 65$ years & $882(29 \%)$ & $358(30 \%)$ & $524(28 \%)$ & \\
\hline GCS score, median (IQR) & $9(5,14)$ & $9(5,14)$ & $9(5,14)$ & 0.92 \\
\hline $3-8$ & $1443(47 \%)$ & $557(47 \%)$ & $886(47 \%)$ & 0.89 \\
\hline $9-12$ & $596(19 \%)$ & $236(20 \%)$ & $360(19 \%)$ & \\
\hline $13-15$ & $1022(33 \%)$ & $402(34 \%)$ & $620(33 \%)$ & \\
\hline Females & $701(23 \%)$ & $348(29 \%)$ & $353(19 \%)$ & $<0.001$ \\
\hline \multicolumn{5}{|l|}{ Pre-admission performance status* } \\
\hline Fit for work or equal & $1872(61 \%)$ & $611(51 \%)$ & $1261(68 \%)$ & $<0.001$ \\
\hline Unfit for work, but independent in self-care & $957(31 \%)$ & $451(38 \%)$ & $506(27 \%)$ & \\
\hline Partially dependent in self-care & $178(6 \%)$ & $99(8 \%)$ & $79(4 \%)$ & \\
\hline Totally dependent in self-care & $54(2 \%)$ & $34(3 \%)$ & $20(1 \%)$ & \\
\hline Significant chronic comorbidity $\dagger$ & $261(9 \%)$ & $136(11 \%)$ & $125(7 \%)$ & $<0.001$ \\
\hline SAPS II score, median (IQR) & $35(23,50)$ & $35(25,50)$ & $35(23,49)$ & 0.059 \\
\hline \multicolumn{5}{|l|}{ Marshall CT classification } \\
\hline DI I & $317(10 \%)$ & $114(10 \%)$ & $203(11 \%)$ & $<0.001$ \\
\hline DI II & $988(32 \%)$ & $350(29 \%)$ & $638(34 \%)$ & \\
\hline DI III & $287(9 \%)$ & $107(9 \%)$ & $180(10 \%)$ & \\
\hline DI IV & $45(1 \%)$ & $11(1 \%)$ & $34(2 \%)$ & \\
\hline EML V/NEML VI & $1424(47 \%)$ & $613(51 \%)$ & $811(43 \%)$ & \\
\hline Craniotomy and hematoma evacuation & $1220(40 \%)$ & $532(45 \%)$ & $688(37 \%)$ & $<0.001$ \\
\hline Decompressive craniectomy & $50(2 \%)$ & $14(1 \%)$ & $36(2 \%)$ & 0.11 \\
\hline External ventricular drain & $156(5 \%)$ & $56(5 \%)$ & $100(5 \%)$ & 0.41 \\
\hline ICP monitoring & $724(24 \%)$ & $248(21 \%)$ & $476(26 \%)$ & 0.003 \\
\hline Mechanical ventilation & $2042(67 \%)$ & $780(65 \%)$ & $1262(68 \%)$ & 0.18 \\
\hline LOS ICU, days, median (IQR) & $2(1,4)$ & $2(1,3)$ & $2(1,5)$ & 0.005 \\
\hline LOS hospital, days, median (IQR) & $6(3,11)$ & $5(3,19)$ & $6(3,11)$ & 0.0012 \\
\hline
\end{tabular}

*A modified World Health Organization/Eastern Cooperative Oncology Group classification system implemented by the Finnish Intensive Care Consortium

${ }^{\dagger}$ Any chronic comorbidity according to APACHE II or to SAPS II

Abbreviations: APACHE, Acute Physiology and Chronic Health Evaluation; DI, diffuse injury; GCS; Glasgow Coma Scale; EML/NEML, evacuated/non-evacuated mass lesion; $L O S$, length of stay; ICP, intracranial pressure; ICU, intensive care unit; SAPS, Simplified Acute Physiology Score; $T B I$, traumatic brain injury 
Table 2 Baseline characteristics and treatment of 1-year survivors of traumatic brain injury patients who had no pre-injury history of psychotropic drug use

\begin{tabular}{|c|c|c|c|c|}
\hline Variables & $\begin{array}{l}\text { All patients without } \\
\text { pre-TBI drug use } \\
(N=1439)\end{array}$ & $\begin{array}{l}\text { Post-TBI psychotropic } \\
\text { medication use }(N=400)\end{array}$ & $\begin{array}{l}\text { No psychotropic medica- } \\
\text { tion use }(N=1039)\end{array}$ & $p$-value \\
\hline Age, median (IQR) & $51(33,63)$ & $53(36,64)$ & $51(31,63)$ & 0.08 \\
\hline $18-40$ years & $472(33 \%)$ & $118(30 \%)$ & $354(34 \%)$ & 0.25 \\
\hline $41-64$ years & $639(44 \%)$ & $185(46 \%)$ & $454(44 \%)$ & \\
\hline$\geq 65$ years & $328(23 \%)$ & $97(24 \%)$ & $231(22 \%)$ & \\
\hline GCS score, median (IQR) & $11(6,14)$ & $9(5-13)$ & $12(7-14)$ & $<0.001$ \\
\hline $3-8$ & $542(38 \%)$ & $191(48 \%)$ & $351(34 \%)$ & $<0.001$ \\
\hline $9-12$ & $309(21 \%)$ & $91(23 \%)$ & $218(21 \%)$ & \\
\hline $13-15$ & $588(41 \%)$ & $118(30 \%)$ & $470(45 \%)$ & \\
\hline Females & $266(18 \%)$ & $84(21 \%)$ & $182(18 \%)$ & 0.13 \\
\hline \multicolumn{5}{|l|}{ Pre-admission performance status* } \\
\hline Fit for work or equal & $1058(74 \%)$ & $270(68 \%)$ & $788(76 \%)$ & 0.003 \\
\hline Unfit for work, but independent in self-care & $330(23 \%)$ & $118(30 \%)$ & $212(20 \%)$ & \\
\hline Partially dependent in self-care & $41(3 \%)$ & $9(2 \%)$ & $32(3 \%)$ & \\
\hline Totally dependent in self-care & $10(1 \%)$ & $3(1 \%)$ & $7(1 \%)$ & \\
\hline Significant chronic comorbidity $\dagger$ & $70(5 \%)$ & $16(4 \%)$ & $54(5 \%)$ & 0.34 \\
\hline SAPS II score, median (IQR) & $30(20,41)$ & $34(24,45)$ & $28(20,40)$ & $<0.001$ \\
\hline \multicolumn{5}{|l|}{ Marshall CT classification } \\
\hline DI I & $179(12 \%)$ & $35(9 \%)$ & $144(14 \%)$ & 0.001 \\
\hline DI II & $587(41 \%)$ & $156(39 \%)$ & $431(41 \%)$ & \\
\hline DI III & $126(9 \%)$ & $35(9 \%)$ & $91(9 \%)$ & \\
\hline DI IV & $18(1 \%)$ & $11(3 \%)$ & $7(1 \%)$ & \\
\hline EML V/NEML VI & $529(37 \%)$ & $163(41 \%)$ & $366(35 \%)$ & \\
\hline Craniotomy and hematoma evacuation & $487(34 \%)$ & $169(42 \%)$ & $318(31 \%)$ & $<0.001$ \\
\hline Decompressive craniectomy & $29(2 \%)$ & $8(2 \%)$ & $22(2 \%)$ & 0.66 \\
\hline External ventricular drain & $79(5 \%)$ & $27(7 \%)$ & $52(5 \%)$ & 0.19 \\
\hline ICP monitoring & $336(23 \%)$ & $114(29 \%)$ & $222(21 \%)$ & 0.004 \\
\hline Mechanical ventilation & $869(60 \%)$ & $290(73 \%)$ & $579(56 \%)$ & $<0.001$ \\
\hline LOS ICU, days, median (IQR) & $2(1,5)$ & $2(1,6)$ & $2(1,4)$ & $<0.001$ \\
\hline LOS hospital, days, median (IQR) & $7(4,12)$ & $8(4-15)$ & $6(4,11)$ & $<0.001$ \\
\hline
\end{tabular}

Analyses do not include those with a history of psychotropic medication use prior to the index hospitalization

*A modified World Health Organization/Eastern Cooperative Oncology Group classification system implemented by the Finnish Intensive Care Consortium

${ }^{\dagger}$ Any chronic comorbidity according to APACHE II or to SAPS II

Abbreviations: APACHE, Acute Physiology and Chronic Health Evaluation; DI, diffuse injury; GCS; Glasgow Coma Scale; EML/NEML, evacuated/non-evacuated mass lesion; $L O S$, length of stay; ICP, intracranial pressure; ICU, intensive care unit; SAPS, Simplified Acute Physiology Score; $T B I$, traumatic brain injury

antidepressants (70\%), hypnotics and sedatives (58\%) and anxiolytics (47\%). Among the 1-year survivors with new use of psychotropic medication, antidepressants (61\%), antipsychotics (35\%) and anxiolytics (26\%) were the most frequently used psychotropic medications. Furthermore, $27 \%$ used multiple psychotropic medications (Supplemental Table 1).

\section{Risk factors for psychotropic medication}

Among the 1439 1-year survivors without a history of pre-TBI psychotropic medication use, a higher GCS score was associated with lower odds (OR 0.93 per point, $95 \%$ CI 0.90-0.96) and a diffuse injury IV was associated with higher odds (OR 3.37, 95\% CI 1.27-9.01, using Marshall 
Table 3 Multivariable logistic regression model showing association between patient demographics, markers of traumatic brain injury severity and psychotropic medication use in 1-year survivors

\begin{tabular}{llr}
\hline Variable & Odds ratio (95\% CI) & $p$-value \\
\hline Age & $1.01(0.99-1.02)$ & 0.130 \\
Sex & 1.0 & \\
$\quad$ Male & $1.31(0.97-1.77)$ & 0.072 \\
$\quad$ Female & $0.93(0.90-0.96)$ & $<0.00$ \\
GCS score & $0.68(0.38-1.22)$ & 0.196 \\
Significant comorbidity & & \\
Pre-admission functional status & 1.0 & \\
$\quad$ Independent in ADL & $0.59(0.30-1.17)$ & 0.135 \\
$\quad$ Dependent in ADL & $1.02(1.00-1.04)$ & 0.101 \\
Modified SAPS II score & & 0.108 \\
Marshall CT class & $0.71(0.46-1.08)$ & \\
$\quad$ DI I & 1.0 & 0.672 \\
$\quad$ DI II & $0.91(0.58-1.41)$ & 0.015 \\
$\quad$ DI III & $3.37(1.27-9.01)$ & 0.635 \\
$\quad$ DI IV & $1.07(0.81-1.41)$ & \\
$\quad$ EML V/NEML VI &
\end{tabular}

Abbreviations: $A D L$, activities of daily living; $C I$, confidence interval; $D I$, diffuse injury; $E M L$, evacuated mass lesion; $G C S$, Glasgow Coma Scale; $N E M L$, non-evacuated mass lesion; SAPS, Simplified Acute Physiology Score

DI II as the reference) of psychotropic medication use (Table 3). In a similar model, using GCS score as a categorical variable and GCS $13-15$ as the reference, GCS of 3-8 had an OR of 1.92 (95\% CI 1.42-2.59) and GCS 9-12 had an OR of 1.46 (95\% CI 1.05-2.04).

After adjusting for TBI severity, an association between craniotomy for hematoma evacuation (OR 1.51, 95\% CI 1.08-2.12) and post-TBI psychotropic medication use was found. No association between ICP monitoring, EVD or decompressive craniectomy and post-TBI use of psychotropics was found (Supplemental Table 2).

\section{Psychotropic medication and mortality}

Of 2305 1-year survivors, 547 patients (24\%) died during follow-up. Median follow-up time was 6.4 years (IQR 4.3-9.3). New psychotropic medication use (OR 1.60, 95\% CI 1.19-2.17) and a history of pre-TBI psychotropic medication use (OR 1.82, 95\% CI 1.19-2.17) were associated with increased odds of late-mortality in 1-year survivors (Table 4).

Including all patients, pre-TBI use of psychotropic medication was not associated with increased odds of 1-year mortality (Supplemental Table 3).
Table 4 Multivariable logistic regression model showing association between use of psychotropic medication and late mortality in 1-year survivors

\begin{tabular}{llr}
\hline Variable & Odds ratio (95\% CI) & $p$-value \\
\hline Age & $1.05(1.04-1.05)$ & $<0.001$ \\
Sex & & \\
$\quad$ Male & 1.0 & $<0.001$ \\
$\quad$ Female & $0.58(0.45-0.76)$ & 0.172 \\
GCS score & $0.98(0.95-1.01)$ & 0.008 \\
Significant comorbidity & $1.68(1.15-2.45)$ & \\
Pre-admission functional status & & \\
$\quad$ Independent in ADL & 1.0 & 0.530 \\
$\quad$ Dependent in ADL & $2.70(1.76-4.12)$ & \\
Modified SAPS II score & $1.01(0.99-1.02)$ & 0.370 \\
Marshall CT class & & 0.953 \\
$\quad$ DI I & $0.82(0.53-1.27)$ & 0.861 \\
DI II & 1.0 & $<0.001$ \\
DI III & $0.99(0.64-1.53)$ & \\
DI IV & $1.10(0.39-3.10)$ & \\
EML V/NEML VI & $1.72(1.35-2.19)$ & \\
Psychotropic medication use & & \\
No & 1.0 & \\
Pre-TBI use & $1.82(1.43-2.30)$ & \\
New post-TBI use & $1.60(1.19-2.17)$ & \\
\hline
\end{tabular}

Median follow-up time was 6.4 years (interquartile range 4.3-9.3)

Abbreviations: $A D L$, activities of daily living; $C I$, confidence interval; $D I$, diffuse injury; $E M L$, evacuated mass lesion; $G C S$, Glasgow Coma Scale; NEML, non-evacuated mass lesion; SAPS, Simplified Acute Physiology Score

\section{Discussion}

\section{Key findings}

In this retrospective multi-centre study, we found that the use of psychotropic medication is common both in patients experiencing TBI and among survivors. Four out of ten patients with TBI used psychotropic medications pre-injury. Among the long-term survivors, three out of ten patients without a history of prior psychotropic medication use were prescribed a psychotropic medication. These figures are notably higher than the use of psychotropic medication (18\%) in the whole adult population in Finland in 2013 [40]. Thus, patients using psychotropic medication are strongly overrepresented among ICU-treated patients with TBI. New post-TBI psychotropic medication use was associated with more severe TBI and appeared especially common in patients needing craniotomy for hematoma evacuation. Importantly, new psychotropic medication use after TBI was associated with an increased risk for late mortality.

Few studies have reported the prevalence of pre- and postTBI use of psychotropic drugs [13, 21]. However, several 
studies have shown the abundance of psychiatric sequelae and illness among TBI survivors: prevalence of $14-77 \%$ for depression, 2-17\% for bipolar disorder, 3-28\% for generalized anxiety disorders and $5-28 \%$ for substance use have been reported [5, 10, 15, 22, 32, 33, 39]. Of patients with ICU-treated severe TBI, approximately $30 \%$ suffer from major depressive disorders and 33\% from major personality change [6]. In comparison, the prevalence of psychiatric symptoms in general ICU survivors seems to range between 17 and $44 \%$ [26, 28, 30, 38]. Thus, the high prevalence of the use of psychotropic medications in the current study is not surprising.

\section{Clinical phenotypes increasing the odds of psychotropic prescription}

Previous studies have found that the severity of TBI correlates with the incidence of psychiatric illnesses [9]. Studies on patients with mild TBI have generally found lower incidences of depression than studies investigating moderateto-severe TBI patients [10, 32, 33]. On the contrary, Jorge et al. [17] did not find an association between the incidence of depression and severity of TBI. It has been speculated that a more severe TBI and its related post-traumatic amnesia may have a protective role for post-traumatic stress disorder (PTSD) and, thus, the relationship between TBI severity and depression is not linear [33, 37]. Furthermore, it has been proposed that the brain injury area location may be more important than general markers of TBI severity such as initial GCS or duration of coma in terms of probability of depression and other psychiatric disorders [8, 17, 33, 37]. Specific locations of lesions in different psychiatric disorders have been found as follows: depression, lower bilateral hippocampal volume [16]; mania, lesions in temporal basal poles [15]; obsessive-compulsory disorder, orbitofrontal cortex, cortex cinguli, nucleus caudatus [3]; psychosis, damage in frontal and orbital lobes [11,36]; alcohol-related disorders, prefrontal cortex volume reduction [18]. These are in-line with our observations that the more diffuse injuries (Marshall CT class IV) can also damage the parts of the brain described earlier, thus specifically causing organic psychiatric disorders.

The Marshall CT classification has not been widely used to classify radiological findings in previous studies dealing with TBI and psychiatric disorders. In the study by Diaz et al., Marshall CT classification or presence of traumatic subarachnoid haemorrhage (SAH) did not associate with post-TBI psychiatric disorder after severe TBI [6]. We found that Marshall CT class IV associated with increased odds of new psychotropic medication use after TBI. This may be interpreted as an association between extensive diffuse brain injury and psychiatric sequela.
Interestingly, we found that craniotomy and hematoma evacuation associated with increased odds of psychotropic medication use, but we did not find a comparable association of the combined Marshall classes V and VI and later medication use. Considering that the cut off $>25 \mathrm{~cm}^{3}$ for the Marshall classes V and VI is purely radiological and arbitrary, it is not that surprising. For example, the variable craniotomy and hematoma evacuation indirectly represents a combination of radiological mass effect, lowered GCS and reasonable patient prognosis. Thus, the craniotomy variable captures more information than the Marshall classification and might be considered as an indicator of a more severe brain injury. However, this finding should be interpreted with caution as it may be affected by several unmeasured factors.

New psychotropic medication use in 1-year survivors was associated with increased odds of late mortality, even after adjusting for TBI severity. Other risk factors for the need of psychotropic medication after TBI are, for example, unfavourable Glasgow Outcome Scale (GOS) [5], history of previous head injury [5], history of psychiatric illness [5, 33], unemployment before TBI [7, 17] and lower levels of education [7]. Thus, psychiatric sequelae after TBI are multifactorial seems to increase risk of late mortality. Early identification of psychiatric comorbidity in TBI survivors may be important to individualize and promote favourable functional and psychosocial recovery.

The very high proportion of patients with TBI combined with a history of psychotropic medication use, the high proportion of new users among TBI survivors and the increased risk of late mortality highlight the need for multi-professional collaboration between fields of neurosurgery, neurology and psychiatrics during the follow-up and rehabilitation of survivors of a TBI. Early identification of potential psychiatric burden and early-stage psychiatric evaluation as the part of multidisciplinary approach in TBI patients might overall influence the final outcomes and necessity of psychiatric medicine initiation and/or psychotherapeutic late interventions, which would require further and more specific investigation. Whether these measures by a multi-professional team could improve outcomes and should be studied.

\section{Strengths and limitations}

Our study has numerous strengths. It is a multi-centre observational study including four out of the five Finnish tertiary ICUs treating TBI patients. This means that our study includes the majority of TBI patients requiring ICU treatment in Finland. The referral population of the four neurointensive ICU's is approximately 3.5 million people, encompassing two-thirds of the Finnish population. We managed to do complete follow-up of the patient medication history as Finland has a government backed tax-funded system for 
drug reimbursement. Virtually all reimbursed prescriptions are entered into the system. Furthermore, the reimbursement decreases the price of drugs that could otherwise prevent patients of the treatment.

A limitation of the study is that we cannot exclude the possibility of off-label prescription of psychotropic medications, which might lead to positive bias in our study. However, negative bias might arise due to the medicine-free treatment (i.e. psychotherapeutic and/or supportive intervention only) of certain psychiatric conditions. Also, we acknowledge the cultural and social influences as a potential factor affecting the threshold for seeking the help of psychiatrist, and thus influencing the compliance of psychotropic drugs use. It should also be highlighted that we used psychotropic medication as a proxy for psychiatric comorbidity. We did not identify specific locations of cerebral contusions. Thus, we could not consider the specific lesions, e.g. damage to frontal and orbital lobes earlier related to psychosis after TBI $[11,36]$. Also, we could not assess the association between pre-trauma socioeconomical factors and risk of psychiatric sequel. The causes of death were not available and, thus, reasons for the increased late mortality in psychotropic medication users remain unclear.

\section{Conclusions}

The use of psychotropic medication in ICU-treated patients with TBI is common. Four out of ten patients had a history of psychotropic medication use prior to the TBI, and among survivors without prior use of psychotropic medication, three out of ten were later prescribed a new medication. A lower GCS score and a diffuse brain injury with midline shift were independently associated with increased odds of future psychotropic medication use. New psychotropic medication use in survivors was associated with increased odds of late mortality. Additional studies are required to define whether early identification and treatment of psychiatric sequelae after TBI could result in more favourable outcomes.

Supplementary Information The online version contains supplementary material available at https://doi.org/10.1007/s00701-021-04956-3.

Author contribution Juho Vehviläinen: study design, manuscript preparation, data analysis, data interpretation

Markus Skrifvars: study design, data acquisition, review and editing, data interpretation

Matti Reinikainen: data acquisition, review and editing, data interpretation

Stepani Bendel: data acquisition, review and editing, data interpretation

Ivan Marinkovic: review and editing, data interpretation

Tero Ala-Kokko: data acquisition, review and editing, data interpretation

Sanna Hoppu: data acquisition, review and editing, data interpretation
Ruut Laitio: data acquisition, review and editing, data interpretation Jari Siironen: study design, data acquisition, review and editing, data interpretation

Rahul Raj: study design, manuscript preparation, data analysis, review and editing, data interpretation

Funding Open access funding provided University of Helsinki including Helsinki University Central Hospital. Independent funding support has been received from Helsinki University Hospital (State funding, Finland VTR TYH2018227); Finska Läkaresällskapet; Medicinska Understödsföreningen Liv \& Hälsa; Svenska Kulturfonden and Maire Taponen foundation. The funders had no role in study design, data collection, data analysis, data interpretation or writing of the manuscript. The first and last author had full access to all the data in the study and had final responsibility for the decision to submit for publication.

\section{Declarations}

Conflict of interest M.S. has received travel grant and lecture fee from BARD Medical (Ireland). J.R. has received lecture fee from Bayer (Finland). These activities have no relation to any of the work presented in this article. Authors I.M. and J.S. have had personal grants from Maire Taponen Foundation. R.R. has had personal grants from Finska Läkaresällskapet, Medicinska Understödsföreningen Liv \& Hälsa and Svenska Kulturfonden. Authors J.V., M.R., S.B., T.A-K., S.H. and R.L. have no competing financial interest to report.

Open Access This article is licensed under a Creative Commons Attribution 4.0 International License, which permits use, sharing, adaptation, distribution and reproduction in any medium or format, as long as you give appropriate credit to the original author(s) and the source, provide a link to the Creative Commons licence, and indicate if changes were made. The images or other third party material in this article are included in the article's Creative Commons licence, unless indicated otherwise in a credit line to the material. If material is not included in the article's Creative Commons licence and your intended use is not permitted by statutory regulation or exceeds the permitted use, you will need to obtain permission directly from the copyright holder. To view a copy of this licence, visit http://creativecommons.org/licenses/by/4.0/.

\section{References}

1. Access Economics (2009) The economic cost of spinal cord injury and traumatic brain injury in Australia. Report by Access Economics Pty Limited for The Victorian Neurotrauma Initiative, Canberra

2. Albrecht JS, Mullins DC, Smith GS, Rao V (2017) Psychotropic medication use among medicare beneficiaries following traumatic brain injury. Am J Geriatr Psychiatry 25(4):415-424

3. Bilgic B, Baral-Kulaksizoglu I, Hanagasi H, Saylan M, Aykutlu E, Gurvit H, Emre M (2004) Obsessive-compulsive disorder secondary to bilateral frontal damage due to a closed head injury. Cogn Behav Neurol 17(2):118-120

4. Colantonio A, Escobar MD, Chipman M, McLellan B, Austin P, Mirabella G, Ratcliff G (2008) Predictors of postacute mortality following traumatic brain injury in a seriously injured population. Journal of Trauma: Injury, Infection \& Critical Care 64(4):876-882

5. Deb S, Koutzoukis C, Ali I, Psych MRC, McCarthy G, Psych MRC (1999) Rate of psychiatric illness 1 year after traumatic brain injury. Am J Psychiatry 156(3):374-378 
6. Diaz AP, Schwarzbold ML, Thais ME et al (2012) Psychiatric disorders and health-related quality of life after severe traumatic brain injury: a prospective study. J Neurotrauma 29(6):1029-1037

7. Dikmen SS, Bombardier CH, Machamer JE, Fann JR, Temkin NR (2004) Natural history of depression in traumatic brain injury. Arch Phys Med Rehabil 85(9):1457-1464

8. Fann JR (1997) Traumatic brain injury and psychiatry. J Psychosom Res 43(4):335-343

9. Fann JR, Burington B, Leonetti A, Jaffe K, Katon WJ, Thompson RS (2004) Psychiatric illness following traumatic brain injury in an adult healthMaintenance organization population. Arch Gen Psychiatry 61(1):53-61

10. Fann JR, Katon WJ, Uomoto JM, Esselman PC (1995) Psychiatric disorders and functional disability in outpatients with traumatic brain injuries. Am J Psychiatry 152(10):1493

11. Fujii D, Ahmed I (2002) Characteristics of psychotic disorder due to traumatic brain injury: an analysis of case studies in the literature. J Neuropsychiatry Clin Neurosci 14(2):130-140

12. Gualtieri CT (1995) The problem of mild brain injury. Neuropsychiatry Neuropsychol Behav Neurol 8(2):127-136

13. Hammond FM, Barrett RS, Shea T, Seel RT, McAlister TW, Kaelin D, Ryser DK, Corrigan JD, Cullen N, Horn SD (2015) Psychotropic medication use during inpatient rehabilitation for traumatic brain injury. Arch Phys Med Rehabil 96(8, Supplement):S256S273.e14

14. James SL, Theadom A, Ellenbogen RG et al (2019) Global, regional, and national burden of traumatic brain injury and spinal cord injury, 1990-2016: a systematic analysis for the Global Burden of Disease Study 2016. Lancet Neurol 18(1):56-87

15. Jorge RE (1993) Secondary mania following traumatic brain injury. Am J Psychiatry 150(6):916

16. Jorge RE, Acion L, Starkstein SE, Magnotta V (2007) Hippocampal volume and mood disorders after traumatic brain injury. Biol Psychiat 62(4):332-338

17. Jorge RE, Robinson RG, Moser D, Tateno A, Crespo-Facorro B, Arndt S (2004) Major depression following traumatic brain injury. Arch Gen Psychiatry 61(1):42-50

18. Jorge RE, Starkstein SE, Arndt S, Moser D, Crespo-Facorro B, Robinson RG (2005) Alcohol misuse and mood disorders following traumatic brain injury. Arch Gen Psychiatry 62(7):742-749

19. Keene AR, Cullen DJ (1983) Therapeutic Intervention Scoring System: update 1983. Crit Care Med 11(1):1-3

20. Knaus WA, Draper EA, Wagner DP, Zimmerman JE (1985) APACHE II: a severity of disease classification system. Crit Care Med 13(10):818-829

21. Kohnen RF, Gerritsen DL, Smals OM, Lavrijsen JCM, Koopmans RTCM (2018) Prevalence of neuropsychiatric symptoms and psychotropic drug use in patients with acquired brain injury in longterm care: a systematic review. Brain Inj 32(13-14):1591-1600

22. Koponen S, Taiminen T, Portin R, Himanen L, Isoniemi H, Heinonen H, Hinkka S, Tenovuo O (2002) Axis I and II psychiatric disorders after traumatic brain injury: a 30-year follow-up study. Am J Psychiatry 159(8):1315-1321

23. Le Gall J-R, Lemeshow S, Saulnier F (1993) Simplified Acute Physiology Score (SAPS II) Based on a European / North American multicenter study. JAMA 270:2957-2963

24. Lewer D, O'Reilly C, Mojtabai R, Evans-Lacko S (2015) Antidepressant use in 27 European countries: associations with sociodemographic, cultural and economic factors. Br J Psychiatry 207(3):221-226
25. Marshall LF, Marshall SB, Klauber MR, Clark MB (1991) A new classification of head injury based on computerized tomography. J Neurosurg 75(11):S14-S22

26. Nikayin S, Rabiee A, Hashem MD, Huang M, Bienvenu OJ, Turnbull AE, Needham DM (2016) Anxiety symptoms in survivors of critical illness: a systematic review and meta-analysis. Gen Hosp Psychiatry 43:23-29

27. Oken MM, Creech RH, Tormey DC, Horton J, Davis TE, McFadden ET, Carbone PP (1982) Toxicity and response criteria of the Eastern Cooperative Oncology Group. Am J Clin Oncol 5(6):649-655

28. Parker AM, Sricharoenchai T, Raparla S, Schneck KW, Bienvenu OJ, Needham DM (2015) Posttraumatic stress disorder in critical illness survivors: a meta-analysis. Crit Care Med 43(5):1121-1129

29. Pickelsimer EE, Selassie AW, Sample PL, Heinemann WA, Gu JK, Veldheer LC (2007) Unmet service needs of persons with traumatic brain injury. J Head Trauma Rehabil 22(1):1-13

30. Rabiee A, Nikayin S, Hashem MD, Huang M, Dinglas VD, Bienvenu OJ, Turnbull AE, Needham DM (2016) Depressive symptoms after critical illness: a systematic review and meta-analysis. Crit Care Med 44(9):1744-1753

31. Raj R, Bendel S, Reinikainen M et al (2018) Temporal trends in healthcare costs and outcome following ICU admission after traumatic brain injury. Crit Care Med 46(4):e302-e309

32. van Reekum R, Bogalo I, Finlayson MAJ, Garner S, Links PS (1996) Psychiatric disorders after traumatic brain injury. Brain Inj 10(5):319-328

33. van Reekum R, Cohen T, Wong J (2000) Can traumatic brain injury cause psychiatric disorders? JNP 12(3):316-327

34. Reinikainen M, Mussalo P, Hovilehto S, Uusaro A, Varpula T, Kari A, Pettilä V, Finnish Intensive Care Consortium (2012) Association of automated data collection and data completeness with outcomes of intensive care. A new customised model for outcome prediction. Acta Anaesthesiol Scand 56(9):1114-1122

35. Richter JC, Waydhas C, Pajonk F-G (2006) Incidence of posttraumatic stress disorder after prolonged surgical intensive care unit treatment. Psychosomatics 47(3):223-230

36. Sachdev P, Smith JS, Cathcart S (2001) Schizophrenia-like psychosis following traumatic brain injury: a chart-based descriptive and case-control study. Psychol Med 31(2):231-9 (Cambridge)

37. Schwarzbold M, Diaz A, Martins ET, Rufino A, Amante LN, Thais ME, Quevedo J, Hohl A, Linhares MN, Walz R (2008) Psychiatric disorders and traumatic brain injury. Neuropsychiatr Dis Treat 4(4):797-816

38. Wang S, Mosher C, Perkins AJ, Gao S, Lasiter S, Khan S, Boustani M, Khan B (2017) Post-intensive care unit psychiatric comorbidity and quality of life. J Hosp Med 12(10):831-835

39. Whelan-Goodinson R, Ponsford J, Johnston L, Grant F (2009) Psychiatric disorders following traumatic brain injury: their nature and frequency. J Head Trauma Rehabil 24(5):324

40. Finnish Statistics on Medicines 2013. Finnish Medicines Agency Fimea and Social Insurance Institution, Helsinki, Finland

Publisher's note Springer Nature remains neutral with regard to jurisdictional claims in published maps and institutional affiliations. 